\title{
Conceptualizing learning experiences: \\ Contributions and mediations of the social, personal, and brute
}

\author{
Stephen Billett \\ s.billett@griffith.edu.au \\ Faculty of Education \\ Griffith University, Australia
}

\begin{abstract}
This paper conceptualizes and elaborates what constitutes learning experiences. It does so from a perspective that centres on experiences as arising through relations between social and personal worlds, yet also acknowledges the mediation of brute facts (i.e., nature). The social contributions are twofold, yet quite distinct. First, there are immediate social experiences that are projected by the particular socially and culturally derived events (i.e., activities and interactions) that individuals encounter, often in circumstances shaped by socially situational and physical factors. Second, there are socio-personal legacies, comprising individuals' cognitive experience, that arise through their ongoing engagements with social experiences throughout life histories. Although socially-derived, these legacies are person-dependent and may be personally idiosyncratic. Importantly, they shape how individuals construe and construct what they experience during, engage with, and learn from these events. Learning experiences, therefore, comprise a negotiation between the suggestions of social and physical world and individuals' construal of what the world projects. These negotiations are also shaped and mediated by brute facts, such as maturation. Underpinning this conception of learning experiences are interdependencies between the social and personal contributions, which are negotiated in ways that are necessarily relational in terms of the exercise of personal agency and the suggestion of social and physical forms. It is through these negotiations that individuals' change or learn and society's norms and practices are remade and transformed. Given this duality, the activities and interactions that comprise learning experiences stand as important bases for understanding: (a) individual change or learning and (b) the ongoing process of remaking cultural practices. It also extends the concept of inter-psychological processes as being relational and needing to include the contributions and mediations of brute facts.
\end{abstract}

\section{Learning experiences}

In this paper, I advance a view about what comprises the experiences through which we learnlearning experiences-by elaborating what contributes to and constitutes such experiences. It is offered from a perspective that positions learning as something mediated by personal, social, and natural factors. This elaboration is prompted by the need to go beyond the immediacy of physical and social contributions to learning experiences in order to account, more fully, for the personal contributions and mediations that shape these experiences. Personal contributions are shaped overtime by social and brute facts that, in turn, both mediate what individuals subsequently experience (i.e., construe and construct) and learn through their encounters with the physical and social world. Such considerations seem necessary and timely. Over the past decade or so, a wide range of settings in which individuals secure rich or worthwhile learning have been considered. This consideration has done much to question the privileging of experiences provided through educational institutions and programs. Instead, other kinds of culturally-derived settings, such as workplaces, have been identified as sites for rich and worthwhile learning. However, as a consequence, many of the recent discussions about learning experiences have come to centre on and privilege the settings where learning is held to occur (e.g., schools, colleges, workplaces, universities). This centering was likely prompted by the situated cognition movement of the 1990s and the contributions of anthropological accounts to understanding processes of learning outside of 
educational institutions and programs. These discussions included a consideration of the potential contributions to learning of those settings and the distribution of opportunities for participation and learning in those settings (e.g., Darrah, 1996). Such accounts have become more sophisticated and now include a consideration of the epistemic qualities of particular kinds of work (e.g., Nerland, 2008). All this helps elaborate the contributions to learning and development that are provided by social and physical settings. However, ultimately, these accounts can only elaborate what individuals' encounter, not what they experience and learn.

Earlier, there was a pervasive and long-term effort to understand and promote the experiencing of learning as being principally an individually-constrained process premised on individuals' possession of and capacity to manipulate knowledge. In many ways, the situated cognition movement sought to redress the predominance of this conception of learning. Building upon and redressing some aspects of its behavioral heritage, cognitive theory advanced individuals' capacity to manipulate their knowledge (i.e., cleverness) as being central to expertise. Cognitive theory posited that experts in a particular domain of activity come to experience (i.e., construe and construct) tasks and activities in ways that are distinct from novices (e.g., Ericsson \& Smith, 1991). Individuals' capacity to process information is emphasized by this perspective and is also understood as dependent upon what information an individual already knew and how they came to know it. This capacity was held to arise overtime-episodically and accumulatively-through countless engagements in domain-specific tasks and the monitoring of task outcomes. These forms of episodic development are necessarily person-dependent, as they occur across individual histories and involve both active engagement and reflection. Individual histories are shaped by the development of capacities and engagement with a task that resides within a particular domain of activities (e.g., occupation, disciplinary field). Here, also the importance of individuals' dispositions (e.g., interest) was seen to shape how and what they engaged with (i.e., construed and constructed). Individuals' dispositions also were held to determine the degree of effort and the kind of intentionality that constituted what they experienced (Perkins, Jay, \& Tishman, 1993). Consequently, from these two distinct perspectives, contributions of the social and physical world were privileged in particular ways,

Less prominent have been perspectives that explain learning experiences from the viewpoint of relations between what the social and physical world provides in the form of immediate experiences (i.e., their affordances) and how individuals personally construe and construct those experiences. The lack of such accounts likely arose from adherence to disciplinary emphases that privilege either the social or individual contributions to that learning. Social contributions have been offered as a solution to an over-emphasis of individual contribution, and possibly, the distinct methodological heritages they both inhabited. However, for researchers who are interested in adults' learning throughout working life, the need to understand what constitutes the learning experiences individuals encounter across their working lives and how they learn from them has generated an imperative to account for both the contributions and relationships between the social settings and individuals' engagement in those settings. It follows that accounts of learning experiences as comprising negotiations between the contributions and press of the immediate social settings and personal purposes (e.g., Fenwick, 2008) and engagement as shaped by individuals' subjectivities, intentions and agency are now becoming more prominent (e.g., Hodkinson, Biesta, \& James, 2008). These relations are also central to elaborating a Vygotskian viewpoint of interpsychological processes and intra-psychological outcomes.

Given the current impetus for reconceptualizing learning experiences as negotiations between the personal and social, it also seems timely to include brute facts-contributions and mediations of the natural world-in discussions about these negotiations. This is necessitated, because, like institutional facts - those generated by social structures and purposes, brute facts, such as the consequences of maturation and (dis)ability - brute facts cannot be wished away (Searle, 1995). Brute facts often mediate how both the social and physical world are transformed, understood, engaged with, and learnt from. Yet, this experiencing of learning is person-specific to some degree. This is because both the mediation of engagement and contribution of institutional 
and brute facts will differ amongst individuals. So, just as physically-demanding tasks might be seen variously as an unwelcome activity, opportunity for exercise, or a chance to demonstrate skill, so too a workplace opportunity might be welcomed as an opportunity or viewed as means by which management is attempting to secure greater commitment and effort. Yet, more fundamentally, how maturation and ability (or disability) plays out for individuals and influences the means through which they can engage (i.e., sense, observe, feel, and hear) with the world beyond their skin is central to what they construe and construct (i.e., learn) from their experience.

With the exception of lifespan development studies and gerontology, considerations of brute facts (such as implications of maturation) are often overlooked in contemporary accounts of learning. The same can be said about disability. The omission of brute facts seems particularly problematic given the current interest in lifelong learning and how individuals maintain the currency of their workplace competence throughout working life. How and what we learn through experience is shaped overtime and mediated by the capacity to experience and engage with the physical and social world. Yet, with maturation and disability arise distinct capacities to engage in these processes across individuals' lives. While maturation inherently benefits children and young adults' active process of learning, for older adults, as reactions slow, some aspects of maturationsuch as diminishing eye sight and lowered energy levels-may constrain these processes (Baltes \& Staudinger, 1996). This is not to suggest an inevitable decline in capacity to experience, but rather that there will be different bases mediating and negotiating encounters..

Of course, all of this could be dismissed as being mere curiosity. Learning experiences occur constantly in our communities and institutions as evidenced by individuals' capacities to undertake activities that they could not do before in ways not attributable to maturity or instructional interludes alone. Yet, how learning experiences are conceptualized is central to understanding human learning and development and how intentional learning experiences are to be thought about, designed, enacted, and appraised. All of this warrants careful and comprehensive elaborations in order to understand the purposes and the efficacy of experiences through which particular kinds of learning arise. Yet, because current conceptualizations (e.g., communities of practice, activity systems, and boundary objects) and practices (e.g., pedagogic efforts) emphasize and privilege the immediate social contributions to these experiences, the role of the personal and persons who are positioned as the learners are often underplayed. In this way, these accounts de-emphasize not only the contributions of the personal in terms of individuals' cognitive experience (i.e., what they know and through which they experience) and the interests and intentions that shape that experience, but also the negotiations between the social suggestion and the inherently personal process of knowledge construal and construction.

It follows then that the aim here is to elaborate an account of learning experiences that encompasses both the personal and the brute-partially to redress the privileging of the immediate social circumstances in current theorizing but, in a way that avoids returning to a highly mentalistic individual orientation. This task encompasses accounting more fully for the negotiations between the personal and the social. It includes making personal subjectivity, sense of self, ambition and interest, and the mediating contributions of brute facts more central elements of subsequent accounts. The broad context for the discussion here is on how individuals learn through their paid work and throughout their working life. This context reflects individuals' learning throughout life more generally — often outside of participation in educational programs - and it is central to the author's concerns and theorizing. However, what is proposed here applies equally to learning through activities that are intentionally directed towards specific kinds of learning (as in educational institutions and programs) and to the locations where teaching predominates. This is because the bases of this account inform learning experiences generally. Indeed, the key premises of the case presented here are that: (a) humans have consciousness and subjectivity that shape their thinking, (b) humans act and learn, and (c) social settings have norms, practices and traditions that shape and transform activities and interactions. Both activities and interactions are subject to demands for change and there is interdependence between the two in realizing these changes. Moreover, in both 
human learning and social transformation, individuals' agency and its exercise are required to bring about purposive change.

Importantly, the discussion here is not about the individual versus the social. Instead, an attempt to find a path between the twin hazards' of individual constructivism, particularly when portrayed as being overly mentalistic, and social determinism (Miller \& Goodnow, 1995). It does this by accounting for the relationship between the personal as a socially shaped entity and the particular sets of suggestions that shape the immediate experiences or events that individuals encounter, negotiate and learn through.

In advancing this case, the paper proceeds as follows. To start, four bases are advanced for considering learning experiences more comprehensively. Next, the negotiated contributions of the personal and the social to what constitutes learning experiences as well as elaborating the informing and mediating roles of brute facts. While this permits the concept of learning experiences to be more inclusive of other kinds of social practices in which individuals participate and learn, it also proposes the need for a broader range of factors and their relative contributions to be more fully considered, acknowledged, and included in accounts of what constitutes learning experiences.

\section{Conceptualizing learning experiences}

There are four reasons to now conceptualize learning experiences more comprehensively in considering learning throughout working life. These reasons are: (a) the active and negotiated character of learning experiences has long been recognized in learning theory, yet is currently under-emphasized; (b) potentially rich learning experiences are widely available and not restricted to participation in educational institutions; (c) distinct kinds of learning experiences and outcomes are afforded by different kinds of socially and physically shaped events; and (d) options for accessing learning experiences and their legitimization are now warranted and urgently required.

First, the active negotiation of what is experienced and its relationship to learning is well established within learning theory. The projective agency of learners and their selective engagement with what they experience in the social world has been long acknowledged (e.g., Baldwin, 1894). This selective engagement is a personal psychological phenomenon that is held to be a product of the active engagement of the person with the socially-derived world they encounter (Baldwin, 1898). Similar development has arisen through children's active engagement with the social world when at play (Vygotsky, 1966 cited in Valsiner, 2000). Hence, the significance of children's agency is emphasized, as is its potential to extend the scope of their learning via the ways in which they elect to engage in play. When engaged in the culturally-derived activity of play, it was children's active and effortful engagement that promoted the scope and depth of their learning. The primary base for the development that arouse through these activities was the quality of the children's engagement (i.e., their intentionality and agency). Similarly, conception of learners seeking to overcome disequilibrium and secure equilibrium (Piaget, 1968), and those seeking to secure viability (von Glasersfeld, 1987) refer to an active process of individuals construing and constructing what they experience and those processes being guided by personal imperatives and intentionality. Analogous here, and from a sociological viewpoint, is individuals' drive to secure ontological security (Giddens, 1984) as a base to understand how learning is experienced and shaped.

Second, individuals learn richly outside of educational institutions and programs and across their working lives. Therefore, we need to understand more fully the qualities of learning experiences. Anthropology also identifies the learning of culturally-derived practices through everyday participation in those practices (e.g., Lave, 1993). This learning is secured through individuals' engagement, observation, and imitation and guidance by more knowledgeable others (Fuhrer, 1993). Workers across a range of industries claim that learning to initially participate in work and maintaining competence throughout working life largely arises through their participation in work activities that are mediated by a combination of personal and situational contributions and imperatives (Billett, 2001). The processes of knowledge construction and its ordering that these workers describe are well acknowledged within both cognitive and social constructivism. Equally, 
the problem-solving ordered learning experiences within cognitive accounts (Anderson, 1993) are not restricted to social practices where intentional instruction occurs. Similarly, securing equilibrium or processes of assimilation and accommodation, viability, the processes of compilation and automation (Anderson, 1982), and the sociocultural accounts of appropriation and microgenetic development (Rogoff, 1990) all emphasize these forms of learning as arising through the negotiation of everyday experiences. Moreover, claims that experiences in particular settings (i.e., educational institutions) are privileged in securing robust learning are easily challenged (e.g., Scribner, 1984). The development of scientific concepts (Glassman, 2001) is not dependent on where they are learnt but whether the concepts were made accessible or not accessible. So, considerations and conceptualizations of learning experiences are not constrained by or limited to environments claiming the intentional promotion of learning as their core purpose. Indeed, these experiences are not restricted to physical spaces, as learning is mediated across time and space by semiotic and other means. It follows that learning experiences are locatable in and through diverse forms of social practices, physically and otherwise mediated circumstances wherever individuals engage in activities and interactions. Consequently, these experiences with their pedagogic practices and potentials need to be understood more fully and deserve being legitimated and accounted for in conceptions of learning.

Third, different contributions provide distinct bases for individuals’ learning. For instance, educational institutions are often unable to provide experiences that represent authentic experiences of practice. Consequently, extensive periods of practice-based experiences are organized in settings where authentic practices can be encountered, engaged, and constructed (e.g., law, medicine, teacher education, and trade apprenticeships). Conversely, experiences in workplace settings, while offering such experiences, may not provide access to forms of propositions and conceptual knowledge that are not-observerable or easily made accessible (Billett, 2001). Yet, these practicebased experiences are often lowly regarded and their pedagogic potential not always acknowledged or maximized. Further, learning experiences outside of educational institutions not only augment what is experienced in those institutions, but are necessitated because of limits to the accessibility, availability, or appropriateness of experiences. For instance, small businesses operators report experiences comprising localized support and their bases for engagement as constituting effective learning experiences for learning local tasks. Similarly, the daily meetings of women, who were bookkeepers for their husbands' small-businesses, in a school car park of as they dropped off and picked up their children, allow for the sharing of and discussion of means to enact a new goods and services tax (Billett, Ehrich, \& Hernon-Tinning, 2003). Collective competence was also developed through participating in discussions during the weekly tennis game by a group of male smallbusiness operators. Both instances represent ways in which "localized" interactions and activities provided social and physical spaces for individuals to engage in effective learning experiences, including monitoring and reflecting on their learning. Yet, despite their potentials and limitations, these kinds of learning experiences sit outside of legitimized conceptions of pedagogic settings and practices.

Fourth, learning experiences, including their contestations, are likely shaped by social and cultural forms. Both constraints on and invitations for participation are enacted in all kinds of social settings and circumstances. Workplaces demonstrate capacities for being discriminatory and adept at reproducing unequal outcomes through practices that are social and cultural in origin (e.g., Bierema, 2001). Such constraints make these learning experiences unavailable, only partly or selectively invitational to some individuals or cohorts, while openly welcoming others. Of course, educational institutions also have procedures that regulate access and progress thereby limiting some cohorts and privileging others’ participation (Bowles \& Gintis, 1976). Likely, all kinds of social practices have ways of regulating participation for their own purposes and needs. Consequently, and given these contestations, what individuals experience, both in and outside of education institutions, can be conceptualized as negotiations between what is afforded to individuals by the social practice and how individuals elect to engage with what is being afforded to 
them. This dualistic and negotiated conception of learning experiences is founded in the relations between their social and personal contributions.

Having outlined some assumptions and premises for understanding and needing to conceptualize learning experiences more comprehensively, it is now necessary to consider in more detail the dualistic (yet relational) nature of these experiences.

\section{Social, ontogenetic and natural bases of learning experiences}

In the previous sections, I argued that it is not sufficient to understand learning experiences as something exercised by the world external to individuals and understood objectively by them, nor is it sufficient to understand learning experiences as entirely phenomenological and wholly individually constructed (as in mentalistic processing). Instead, these experiences are, on the one hand, something negotiated between what the physical and social world suggests or projects, and, on the other hand, individuals' construal and construction of that suggestion. That is, learning experiences comprise a duality between the institutional and brute facts that are encountered and individuals' subjective interpretation of and engagement with them. The suggestions of the social and brute world range from being those that are strongly compelling to those that some individuals are either unaware of or can easily brush aside. Hence, the social world is not deterministic because it is unable to project its message comprehensively and uniformly, and individuals differ in how they construe and take up that message (Berger \& Luckman, 1967). For instance, adolescent fads may be lost on their parents (Valsiner, 2000). Further, individuals' engagement with what they experience is shaped by their intents, interest, access to particular kinds of discourses, values and societal sentiments, as well as the brute facts that comprise their level of energy, state of fatigue, and emotion. This renders these to be person-specific, inter-psychological processes. These bases are advanced as being useful to understand more fully the experiences through which we learn. Further, these negotiations are likely to be common to individuals' engagements with the physical and social world, albeit exercised in distinct ways, and with greater or lesser effect.

The legacy of these negotiated experiences is twofold: (a) inciting individual learning and (b) the remaking of culture. Just as individuals need to access and construct the knowledge that has been generated through history, culture, and situation to participate in culturally-derived practices (Cole, 1998), the social world requires the agency of individuals for it to be remade and transformed (Giddens, 1984). It is unnecessary and unhelpful for individuals to engage in Crusoe-like epistemological activities to learn what is already known. Instead, individuals need to engage with what is known phylogenetically (i.e., development across the history of the human race), albeit conditionally in response to particular imperatives that are socially-situated and exercised at particular moments in time. For instance, the constant process of remaking occupational activity occurs by applying and adapting historically- and culturally-derived knowledge to particular workplace circumstances and tasks, and at a particular moment in time in response to the changing requirements of that work, which itself arises as a cultural imperative. In this way, the contributions of the personal and social are interdependent because alone neither is sufficient to bring about either change to cultural practices or change in individuals' cognition. Yet, this duality is of the relational kind because it is shaped in different ways by the contributions of the personal and social. Therefore, it follows that to understand what constitutes learning experiences requires an elaboration of both the duality between the world beyond the person and the personal, and the negotiations that comprise this duality. Much of this has been advanced as a relational interdependence between individual and social contributions (Billett, 2006). As an interpsychological process, it comprises the engagement between the "immediate experiences" as projected by social and brute contributions, including situational factors, and individuals' "cognitive experiences" that arise through earlier or pre-mediate social experiences (Valsiner, 2000). In all, the conception of learning experiences as advanced above is defined as: comprising negotiations between (a) what the social and physical worlds suggest and project, and (b) individuals' construal and construction of these experiences, as shaped by their socially-shaped personal histories, which includes the mediating role of brute facts, such as maturity. 
Building upon the discussions above, the following sections elaborate this conception. Figure 1 offers a depiction of this elaboration. Its core elements are principally three-fold: (a) suggestions from the social and physical world, (b) individuals' cognitive experience, and (c) relational negotiations between them. In this figure are depicted the distinct forms of development occurring within the dualities of the suggestion of the physical and social world and individuals' cognitive experience. For the suggestion of the world beyond the individual, there are particular kinds of contributions and legacies (i.e., remaking and transformation of culture), as there are for individuals' cognitive experience or intra-psychological attributes (i.e., ontogentic development). The contributions to these dualistic elements are both drawn upon and transformed through these negotiations. For the suggestion of the social and physical world, these comprise the kinds of activities, discourses, practices and norms, values, and cultural subjectivities that constitute those practices. For individuals' cognitive experience, they comprise personal intentions, sense of identity, subjectivity, individual capacities, including their access to discourses, knowledge, and their organization. These contributions comprise the bases for dualities that are both relational and negotiated. The outcomes of this negotiated duality are generative of legacies in the form of remaking and transforming culture as well as ontogenetic development. These elements are now discussed to conceptualize learning experiences.

Figure 1 about here in landscape

\section{Suggestion of the social and physical world}

The contributions to learning experiences of the social and physical world are expressed through their suggestions to individuals. The projection of these suggestions may be weaker or stronger. These contributions are held as the concept of the gift of the social (Archer, 2000) and of both institutional facts (i.e., social practices and other suggestions) and brute facts (i.e., contributions of nature) (Searle, 1995). Neither of these kinds of facts can be wholly wished away because they shape the social and physical circumstances in which individuals come to experience. However, although not always able to be wished away, individuals elect how they respond to these facts. For instance, factors such as workplace norms and values might be either wholly embraced or resisted by individual workers or the through the range of participatory practices exercisable between these two positions. Therefore, rather than accepting and coming to identify with a set of practices and values in an education program, individuals might chose to dis-identify with those practices and ultimately withdraw from that social practice (Hodges, 1998). The suggestion of the social (e.g., workplace norms and practices) will be more or less potent, depending upon individuals' standing in their social practices, as well as their willingness to comply with those practice's norms and values. For instance, in hairdressing salons, the prospect for operating outside the culture of practice (i.e., "what we do here is...") is taken up more by owners and mangers, than apprentices who are expected to conform to those practices (Billett, 2003). In this way, institutional facts such as these contribute to what is encountered and can be exercised in terms of socially-organized and ordered norms and practices (e.g., language, discourse, queuing, turn taking). This includes the historically, culturally, and socially constituted practices, such as the mediational qualities of language and symbols as well as the situation-specific norms and practices individuals encounter in workplace settings. The social contribution or gift is also evident in individuals' pre-mediate experiencesones occurring earlier that have secured particular ontogenetic legacies (Valsiner \& van der Veer, 2000). That is, the person-specific, intra-psychological attributes constructed through a lifetime of inter-psychological experiences. As foreshadowed, these person-specific legacies subsequently shape how individuals construe, construct, and engage with what they encounter.

In this way, the gifts of the historical, cultural, and situational-derived contributions or institutional facts are generative of the knowledge required to engage in culturally-sourced and sanctioned activities, such as those enacted in work, family, and community lives. The socially- 
shaped physical world also exercises pedagogic properties projected through the physical environment and artefacts that individuals encounter. The arrangement of pews and pulpit in a church do much to define the kind of relations and interactions tolerated there (Barker, 1968). These arrangements are product of cultural practices and longstanding arrangements that are implicit in and reinforced through social practices such as in schools and workplaces. Whether it is to secure the learning of the defined body of knowledge (Gauvain, 1993), provide clues and cues (Lave, Murtaugh, \& de la Roche, 1984), or declare certain tasks and location as being either on or off limits (Barker, 1968), the physical environment contributes in shaping the activities and interactions individuals encounter and use to negotiate what they learn. Other studies concur. A bar worker, for instance, referred to the context as richly informing her about the drinks her customers ordered, which allowed her to conduct her work effectively, and a warehouse worker referred to the informing qualities of the library of examples for practice that her workplace afforded (Billett, 2001). These kinds of contributions have been used to explain standing patterns of behaviour (Barker, 1968). Yet, when taken as being deterministic such patterning denies a significant role for human agency (Stokols, 1977). Although the contributions of physical setting might aid cognition, they do not direct it.

Importantly, therefore, contributions of the social-physical world through the provision of cues and clues, shapes and suggests rather than determines what is experienced. Even those proposing a strong social influence acknowledge a central role for the personal, because for instance, no amount of surveillance or monitoring can control desire (Foucault, 1986). Similarly, this personal agency is necessarily exercised in the process of appropriating, mastering, or rebuffing the social suggestion. Indeed, an agentic role is necessary for individuals to understand and respond to the social suggestion because it is not inherently pervasive (Berger \& Luckman, 1967).

Consequently, even if faithful reproduction of the social world is being aimed for, the limits of the projection of the social suggestion necessitate individuals' active remaking of cultural practices since the suggestion is not always available or unambiguous.

The contributions of brute facts, such as ageing and disability, also cannot be ignored, although they can be negotiated to some degree. For instance, while reaction times might slow over time, it seems the repertoires of knowledge of older workers can compensate for these maturation processes. There is also the coming together of brute and social facts that exercise their suggestion in particular ways. Studies of employer investment in employees' development indicate a privileging of youth over age, with younger workers far more likely to be granted employer support for their further development than older workers (O'Connell, 1999). Preference is granted to the older employees only when they are "last resort" employees (Quintrell, 2000). Hence, the suggestion being projected is that an employee's age will shape the invitational qualities of their employment. Yet, in some kinds of employment there is an acknowledgement and accommodation of the brute fact of ageing. Fire-fighters, whose personal identity is often tightly aligned to their occupation, at a certain age can be given options that allow them to continue to identify as a firefighter through forms of this work that do not require the physical strength of a front-line firefighter (Smith \& Billett, 2006).

In these ways, the social and physical world provides and exercises its suggestions in situation-specific ways and with different potency depending on the circumstances of their exercise. All of this comprises facts that constitute the socially and physically-derived experience beyond the skin. Yet, these facts comprise suggestions that individuals encounter in different ways, as experienced by them, and mediated by individuals' cognitive experience.

\section{Individuals’ cognitive experience}

Individuals' construal and construction of what they encounter is constituted by their cognitive experience, which is a product of ontogenetic development (i.e., through their life history). It comprises what they know and how they know it as well as the intra-psychological base for construing and constructing what is subsequently encountered. Although having strongly social geneses, arising through ongoing and moment by moment negotiations with the social world (i.e., 
inter-psychologically), individuals' cognitive experience is likely to be person-specific in some ways. Importantly, this is not to suggest an ad hoc form of relativism. Instead, individuals' constructions are premised on an ontological platform comprising unique personal histories arising through inter-psychological relations (i.e., between social suggestions and individuals' cognitive experience). Individuals privately construe, cognise, or interpret the world as they encounter it in a process referred to earlier as constructive alternativism (Kelly, 1955). As noted, children learn to expect non-predictability in social interactions and their outcomes (Baldwin, 1898). This positions and prepares them to expect to deal with the world in terms of variability, rather than stability: requiring an active engagement with social forms to construe meaning and intent. This active enactment of the cognitive experience was subsequently rehearsed by Piaget and von Glasersfeld, as discussed earlier. Moreover, individuals' cognitive experience has to be in some ways personally shaped and possibly idiosyncratic since each individual has negotiated a unique set of interpsychological experiences throughout their life history. This leads them to construe what they encounter (i.e., immediate experiences) in particular ways. For instance, what constitutes either a routine or non-routine learning experience is premised on what individuals have previously encountered, making these experiences person-dependent to some degree. The degree of novelty that characterises the experience (and, therefore whether it constitutes transformational learning or refinement of what is already known) can only be premised in personal histories.

This personal-social legacy arises inter-psychologically through microgenetic development or moment by moment learning comprising engagement in everyday conscious goal-directed activities that are largely social in origin. It both requires the deployment of and realises change in individuals' cognitive experience (i.e., learning). From a post-structural viewpoint: the particular character of an individual's gaze-how he or she views and makes sense of the world (Keith \& Pile, 1993), comprises such an instance. The salient point here is that the construal of experiences will differ across those engaging in the same physical and social environment due to distinct pre-mediate experiences leading to particular ways of experiencing the observed and felt world. Hence, there is a need to go beyond situated accounts to explain what constitutes learning experiences. However, this is not to deny the role of the social world because ultimately such a perspective exercises a healthy respect for the world as it is (Kelly, 1955). Indeed, well-rehearsed procedures are enacted almost automatically and are the subject to socially derived dispositions (Bourdieu, 1991). The most apparently solitary actions of workers (e.g., lighthouse keepers) are paragons of socially-shaped action (Scribner, 1992). Similarly, the private task of reading is only made possible because of the social effort that generates a literate society with its texts, reasons to read, and systems of organising written material (Rogoff, 1990). Nevertheless, because the relation between the individual and social experience stands to be unique in some ways, learning experiences comprised of engagement in activities that are more or less closely socially guided can be quite individually and personallyconstituted.

The outcome of these construals and constructions-individuals' intra-psychological attributes — subsequently shape their inter-psychological experience between the immediate and pre-mediate social experience (e.g., the learning experiences they encounter) and individuals' ontogeneses. In particular, these relations point to the role of personal agency and intentionality in how what is observed, heard, and felt is construed and constructed. These have been referred to as intention in action (Searle, 1995). This is because the causal power of social forms is mediated through human agency, which is underpinned by personal direction, intentionality, and energy. The focus of human agency is directed towards something. Desires, for example, may be directed towards objects and beliefs or towards states of affairs (Searle, 1983) with intentionality being the "property of actions that make ordinary people and scholars alike call them purposeful, meant, or done intentionally” (Malle, Moses, \& Baldwin, 2001, p. 3). The necessity of human agency also emphasises the salience of individuals' intentionality (however apparently unintentional). For instance, visual affordances are not found inherently in the object, but in what the individual extracts from the object, thereby placing an emphasis on both the object and the subject (Gibson \& Levin, 1975). Yet, in all of this, it is perhaps our conscious thought that is most subject to the 
whims of our subjectivity and the frailties of human cognition, including the emotionality and just plain wooliness of our thinking and acting. Indeed, our "subjectivity is primarily on experience, and remains firmly open to inconsistency, contradiction and unselfconsciousness” (Mansfield, 2000, p. 6). These are probably most likely when the brute facts of weariness, frustration, and heightened emotion are at play. So, whether referring to learning experiences in physical, social, or semiotic forms, individuals' subjectively exercised agency, intentionally, and effort are what ultimately comprise "experience."

In this way, it is the exercise and coming together of the both the suggestion of the world beyond individuals and their personal subjectivity, agency, and intentionality that constitutes and negotiates learning experiences.

\section{$\underline{\text { Relational negotiations within inter-psychological processes }}$}

It follows that the negotiations between social forms and individuals that constitutes learning experiences comprise a duality between the suggestion of the social and physical world and individuals taking up that suggestion. Yet, it is unlikely that these negotiations will ever be mutual or reciprocal-equally shared or balanced across the contributions of the social and personal. Instead, they are most likely to be relational. Individuals have personally particular bases for interacting with social partners and the social suggestions they encounter; these suggestions are exercised in ways, that are more or less compelling and in different ways for different individuals. Consider, for instance, the distinct bases for these negotiations between the person employed in a workplace and the fleeting visitor. Even with this example, the taking up of what individuals experience can be whole-hearted and full-bodied, as in appropriation, or the taking up of what individuals experience can be partial and half-hearted at best, as in mastery (Wertsch, 1998), depending on their interest or concurrence with what is encountered. This is because both the social suggestion and individual subjectivities are unlikely to ever be arrayed and aligned in ways that permit them to be described as being mutual or shared in equal part. These relational bases shape with whom to interact, how those interactions proceed, and what is changed (both cultural and individual) through these processes. The same stimuli, activities, interactions, and artifacts will result in quite diverse learning experiences for different individuals because of their personal construals. In its most intense form, social agency is held to be strongly compelling and subjugating. However, the potency of social suggestion is likely mediated by individuals' agency (e.g., the parent instructing a child, the child resisting the parental request), but more commonly it is quite pervasive in its forms, being almost invisible and deployed through everyday practices that subtly and over time work to secure particular outcomes in individuals (e.g., McLaren, 1997). Yet, there will be situations where the social suggestion will: (a) simply remain unknown to or not perceived by individuals, (b) not be engaged with by individuals due to disinterest, or (c) be actively disassociating with by the individuals. Indeed, if the social suggestion was clear, unequivocal, and uniformly pervasive there would be no need to communicate since meaning would be commonly understood (Newman, Griffin, \& Cole, 1989).

So, in these ways, the social suggestion is not always effectively exercised because its expression is inevitably unclear, unequivocal, and incomplete. Also, not all engagements in social practice are as enculturating as those of the Angolan tailors' apprentices who worked and lived in a master tailors' house on a street filled with similar houses (Lave \& Wenger, 1991). There are many social practices that we engage with fleetingly and/or without commitment or interest. Conceptions of distributed cognition, activity systems, and boundary objects presume that individuals are aware of and engage with these institutional artifacts. Yet, unless individuals understand the syntaxes, rules, and semantic content of what is being communicated, it may be lost to them (Searle, 1984). So, these interactions represent processes with outcomes that cannot be predetermined (i.e., externally determined). Instead, the processes and impacts are relational: they are not wholly a product of neither personal agency, nor of social suggestion. More than just mentalistic cognitive processes of enactment and engagement, the bases for human interactions are also premised within their desires, interests, goals, and other forms of intention that direct personal epistemologies. 
These, like other aspects of individuals' experience, are products of pre-mediate experiences - those occurring earlier and being shaped by the intersections between individual and personal agency across life histories.

The discussions about negotiations between social and individual agency-interpsychological processes - necessarily need to account for the natural world or brute facts, a consideration that is often absent from both social and individual constructivist accounts. Like the social suggestion or institutional facts, these factors cannot always be wished away and are also experienced in personally specific ways. Brute facts, such as ageing and disability, are perhaps the most unreasonable and un-negotiable. In different ways, both social and individual contributions to what constitutes a learning experience are shaped by the natural world. The social genesis of knowledge is founded on cultural need and evolves by responding to the changing requirements of cultural practices, such as changes in the requirements for occupations. Yet, the natural world generates much of this requirement for change and, hence, the cultural response. For instance, the requirement for shelter, food, and transport are determined by nature, albeit exercised by sociallyderived responses. The need for human services (e.g., hair cuts), the production of food, the production of warm clothing, the healing and nursing of the sick, and so on, are all products of brute facts. The kinds of tools that humans have developed collectively and culturally, and perfected overtime are often devices derived to assist attempts to control, manipulate, overcome, or just manage the natural world (Vygotsky, 1978). The brute facts of time and distance have also lead to technologies that attempt to overcome their constraints. In these ways, much of the cultural genesis of knowledge-particularly knowledge for the vocational actor-has its source in nature or brute fact.

Moreover, ontogenetic development is also shaped by maturation, albeit in ways that are different across the human population (Baltes \& Staudinger, 1996): another brute fact. This maturation is particularly helpful for children and young adults, yet serves older humans less well as reaction times, strength, physical faculties, and memory become diminished (to varying degrees). Indeed, this causes older humans to seek support in cultural artifacts, perhaps in ways and by degrees that younger adults and children may not require. So the process of getting older is part of ontogenetic development and shapes both the goals for and processes of negotiating with what is encountered in the physical and social world and in person-specific ways. Disability, which comes together with aging for most of us, also plays out in person-particular ways and shapes how disabled workers are able to engage in work activities and interactions (Church, 2004). Certainly, much of the knowledge needed to be learnt in order to participate in everyday cultural activities such as work are derived from social partners and sources through interactions and engaging in activities that have a socio-historical genesis: through inter-psychological processes. Yet, the experiences of individuals' engagement with those sources generate how their epistemological actions and agency develop. These personal epistemological outcomes (i.e., intra-psychological outcomes) are exercised for personal and social purposes through learners' epistemological agency, which is itself both shaped and constrained by the imperatives of social and physical settings. The kinds of affordances that constitute these practices are likely those which order and sequence learning experiences in ways that permit individuals to progress. The provision of practice and guidance also stand as the pedagogic properties afforded by the social practice. The pedagogic and regulatory discourses of particular settings come together to regulate and constituted pedagogic properties. Yet, beyond these properties is an individual's epistemological agency, which also constitutes a key pedagogic element. It is this agency that will direct their energy, selectivity, and capacities and thereby shape the intensity and duration of their engagement, as well as shape the processes of remaking and transforming the culture.

In sum, I have attempted to elaborate what constitutes learning experiences through a consideration of the duality between contributions of the social and personal worlds, which are in turn shaped by the brute facts of maturation. My purpose is to transcend accounts that privilege what occurs in situated practice or what occurs through individualistic orientations. Instead, I propose that the elements of learning experiences are threefold. First, the social world provides 
norms and practices as well as purposes for learning. Moreover, the social world projects its suggestion through its norms, practices, and artifacts that comprise the immediate experience we engage with across different kinds of social settings. Second, individuals' cognitive experience (i.e., what they know, how they know it, and how they make sense of what they experience) shapes their construal and construction of their engagement with a social and brute world. The personal emphasis is important because individuals' cognitive experiences arise through individuals' unique personal history or ontogeny and this shapes how they make sense of both the brute and the social world. Third, is the brute world that both contributes to what is encountered and that mediates individuals' construals of these events. These contributions extend from the imperatives of physicality, and physiological needs to the ways in which maturation shape humans capacities for engagement, participation and, hence, learning. In these ways, the conception of inter-psychological processes needs extending to include consideration of the brute facts that shape both social purposes and sources as well as how individuals subjectively construe and construct what they encounter through their engagements with a social and physical world.

In conclusion, the contributions advanced here are threefold. First, much theorizing in recent times has given emphases to either the individual (e.g., cognitive theories) or the social (e.g., sociocultural theories). The relational quality of the duality between the personal and social in learning and what constitutes learning experiences is proposed as offering a pathway between social and individual determinism. Second, the contribution of brute facts, elements of the natural world which we cannot wish away, are brought more central and posited as important mediating factors in what constitutes the experiencing of the physical and social world in the process of learning. Third, conceptions of inter-psychological processes are extended beyond considerations of social and personal contributions to include the physical world of brute facts. In all, these contributions elaborate a basis for considering pedagogic practices constituting both the social practice's affordances and individuals' epistemological efforts. These contributions are unlikely to be limited to considerations of adult learning in and throughout their working lives.

Acknowledgement. I want to acknowledge the constructive and supportive engagement of the editor in the further development of this manuscript, and also to Tamara Jackson for some helpful editing.

\section{References}

Anderson, J. R. (1982). Acquisition of cognitive skill. Psychological Review, 89(4), 369-406.

Anderson, J. R. (1993). Problem solving and learning. American Psychologist, 48(1), 35-44.

Archer, M. S. (2000). Being Human: the problem of agency. Cambridge: Cambridge University Press.

Baldwin, J. M. (1894). Personality-suggestion. Psychological Review, 1, 274-279.

Baldwin, J. M. (1898). On selective thinking. The Psychological Review, V(1), 1-24.

Baltes, P. B., \& Staudinger, U. M. (1996). Interactive minds in a life-span perspective. In P. B. Baltes \& U. M. Staudinger (Eds.), Interactive minds: Life-span perspectives on the social foundations of cognition (pp. 1-34). Cambridge: Cambridge University Press.

Barker, R. G. (1968). Ecological psychology: Concepts and methods for studying the environment of human behaviour. Stanford: Stanford University Press.

Berger, P. L., \& Luckman, T. (1967). The social construction of reality. Harmondsworth, Middlesex: Penguin Books.

Bierema, L. L. (2001). Women, work, and learning. In T. Fenwick (Ed.), Sociocultural perspectives on learning through work (pp. 53-62). San Francisco: Jossey Bass/Wiley.

Billett, S. (2001). Learning in the workplace: Strategies for effective practice. Sydney: Allen and Unwin.

Billett, S. (2003). Sociogeneses, activity and ontogeny. Culture and Psychology, 9(2), 133-169.

Billett, S. (2006). Relational interdependence between social and individual agency in work and working life. Mind, Culture, and Activity, 13(1), 53-69. 
Billett, S., Ehrich, L., \& Hernon-Tinning, B. (2003). Small business pedagogic practices. Journal of Vocational Education and Training, 55(2), 149-167.

Bourdieu, P. (1991). Language and symbolic power (J. B. Thompson, Ed. and G. Raymond, \& M. Adamson, Trans.). Cambridge: Polity Press.

Bowles, S., \& Gintis, H. (1976). Schooling in capitalist America. New York: Basic Books.

Church, K. (2004). Dancing Lessons: A Choreography of Disability in Corporate Culture. Paper presented at the WALL Annual Meeting, Toronto.

Cole, M. (1998). Can cultural psychology help us think about diversity? Mind, Culture and Activity, 5(4), 291-304.

Darrah, C. N. (1996). Learning and Work: An Exploration in Industrial Ethnography. New York: Garland Publishing.

Ericsson, K. A., \& Smith, J. (1991). Towards a general theory of expertise. Cambridge: Cambridge University Press.

Fenwick, T. (2008). Women's learning in contract work: Practicing contradictions in boundaryless conditions. Vocations and Learning, 1(1)

Foucault, M. (1986). The care of the self: The history of sexuality (Vol. 3,R. Hurley, Trans.). Harmondsworth: Penguin.

Fuhrer, U. (1993). Behaviour settings analysis of situated learning: the case of newcomers. In S. Chaiklin \& J. Lave (Eds.), Understanding practice: Perspectives on activity and context (pp. 179-211). Cambridge, UK: Cambridge University Press.

Gauvain, M. (1993). The development of spatial thinking in everyday activity. Development Review, 13(1), 92-121.

Gibson, E. J., \& Levin, H. (1975). Psychology of reading. Cambridge, Mass: MIT Press.

Giddens, A. (1984). The constitution of society. Cambridge: Polity Press.

Glassman, M. (2001). Dewey and Vygotsky: Society, Experience, and Inquiry in Educational Practice. Educational Researcher . 30(4), 3-14.

Hodges, D. C. (1998). Participation as dis-identification with/in a community of practice. Mind, Culture and Activity, 5(4), 272-290.

Hodkinson, P., Biesta, G., \& James, D. (2008). Understanding learning culturally: Overcoming the dualism between social and individual Views of Learning. Vocations and Learning, 1(1).

Keith, M., \& Pile, S. (Eds.). (1993). Place and politics of identity. London: Routledge.

Kelly, G. A. (1955). The psychology of personal constructs New York: Norton.

Lave, J. (1993). The practice of learning. In S. Chaiklin \& J. Lave (Eds.), Understanding practice: Perspectives on activity and context (pp. 3-32). Cambridge, UK: Cambridge University Press.

Lave, J., Murtaugh, M., \& de la Roche, O. (1984). The dialectic of arithmetic in grocery shopping. In B. Rogoff \& J. Lave (Eds.), Everyday Cognition: Its development in social context (pp. 76-94). Cambridge, Mass: Harvard University Press.

Lave, J., \& Wenger, E. (1991). Situated learning - legitimate peripheral participation. Cambridge, UK: Cambridge University Press.

Malle, B. F., Moses, L. J., \& Baldwin, D. A. (2001). Introduction: The significance of intentionality. In B. F. Malle, L. J. Moses \& D. A. Baldwin (Eds.), Intentions and Intentionality: Foundations of Social Cognition (pp. 1-26). Cambridge, Massachusetts: The MIT Press.

Mansfield, N. (2000). Subjectivity: Theories of the self from Freud to Haraway. Sydney: Allen and Unwin.

McLaren, M. A. (1997). Foucault and the subject of feminism. Social Theory and Practice, 32(1), 109-128.

Miller, P. J., \& Goodnow, J. J. (1995). Cultural practices: Towards an integration of culture and development. In J J Goodnow, P. J. Miller \& F. Kessel (Eds.), Cultural Practices as Contexts for Development (Vol. 67, pp. 5-16). San Francisco: Jossey Bass. 
Nerland, K. (2008). Knowledge cultures and the shaping of work-based learning: the case of computer engineering. Vocations and Learning, 1(1).

Newman, D., Griffin, P., \& Cole, M. (1989). The construction zone: Working for cognitive change in schools. Cambridge, UK: Cambridge University Press.

O'Connell, P. J. (1999). Adults in training: An international comparison of continuing education and training. Paris: OECD.

Perkins, D., Jay, E., \& Tishman, S. (1993). Beyond abilities: A dispositional theory of thinking. Merrill-Palmer Quarterly, 39(1), 1-21.

Piaget, J. (1968).. Structuralism (C. Maschler, Trans. and Ed.). London: Routledge \& Kegan Paul.

Quintrell, M. (2000). Older and wiser; or just at the end of the line? Westminster Studies in Education, 23, 19-31.

Rogoff, B. (1990). Apprenticeship in thinking - cognitive development in social context. New York: Oxford University Press.

Scribner, S. (1984). Studying working intelligence. In B. Rogoff \& J. Lave (Eds.), Everyday cognition: Its development in social context (pp. 9-40). Cambridge, Mass: Harvard University Press.

Scribner, S. (1992). Mind in action: A functional approach to thinking. The Quarterly Newsletter of the Laboratory of Comparative Human Cognition, 14(4), 103-110 (Reprint of 1983 lecture).

Searle, J. R. (1983). Intentionality: An essay in the philosophy of the mind. Cambridge: Cambridge University Press.

Searle, J. R. (1984). Brains, minds and science. Harvard: Harvard University Press.

Searle, J. R. (1995). The construction of social reality. London: Penguin.

Smith, R., \& Billett, S. (2006). Interdependencies at work: Constituting reflection, performance, dialogue and reward. Journal of Adult and Continuing Education, 12(2), 156-169.

Stokols, D. (1977). Origins and directions of environment-behavioural research. In D. Stokols (Ed.), Perspectives on environment and behavior theory, research and application. New York: Plenium Press.

Valsiner, J. (2000). Culture and human development. London: Sage Publications.

Valsiner, J., \& van der Veer, R. (2000). The Social Mind: The construction of an idea. Cambridge, UK: Cambridge University Press.

von Glasersfeld, E. (1987). Learning as a constructive activity. In C. Janvier (Ed.), Problems of representation in the teaching and learning of mathematics. Hillsdale, NJ: Lawrence Erlbaum.

Vygotsky, L. S. (1978). Mind in society: The development of higher psychological processes. Cambridge, Mass: Harvard University Press.

Wertsch, J. V. (1998). Mind as action. New York: Oxford University Press. 